\title{
Influence of TGFB1 C-509T polymorphism on gastric cancer risk associated with TGF- $\beta 1$ expression in the gastric mucosa
}

\author{
Yoon Jin Choi $\cdot$ Nayoung Kim $\cdot$ Aesun Shin $\cdot$ Hye Seung Lee $\cdot$ Ryoung Hee Nam • \\ Hyun Chang · Cheol Min Shin · Young Soo Park · Dong Ho Lee • \\ Ji Hyun Park $\cdot$ Hyun Chae Jung
}

Received: 23 March 2014/ Accepted: 22 July 2014/Published online: 14 August 2014

(c) The International Gastric Cancer Association and The Japanese Gastric Cancer Association 2014

\begin{abstract}
Background Transforming growth factor- $\beta 1$ (TGF- $\beta 1$ ) has dual roles inhibiting and promoting carcinogenesis. Although many researchers have conducted association studies between TGFB1 C-509T polymorphism and the risk of developing gastric cancer, the results are not uniform.

Methods We genotyped 1028 gastric cancer patients and 958 controls by the polymerase chain reaction-restriction fragment length polymorphism method. Immunohistochemistry was performed to assess the expression of TGF$\beta 1$ in the cancer and noncancerous tissues of 120 gastric cancer patients. mRNA expression was also measured in noncancerous gastric mucosa by qRT-PCR in the 282 subjects.
\end{abstract}

Electronic supplementary material The online version of this article (doi:10.1007/s10120-014-0412-9) contains supplementary material, which is available to authorized users.

Y. J. Choi · N. Kim $(\bowtie) \cdot$ R. H. Nam · H. Chang ·

C. M. Shin · Y. S. Park · D. H. Lee

Department of Internal Medicine, Seoul National University

Bundang Hospital, 173-82, Gumi-ro, Bundang-gu, Seongnam,

Gyeonggi-do 463-707, South Korea

e-mail: nayoungkim49@empal.com

N. Kim · D. H. Lee · J. H. Park · H. C. Jung

Department of Internal Medicine and Liver Research Institute, Seoul National University College of Medicine, Seoul,

South Korea

A. Shin

Department of Preventive Medicine, Seoul National University College of Medicine, Seoul, South Korea

H. S. Lee

Department of Pathology, Seoul National University Bundang Hospital, Seongnam, Gyeonggi-do, South Korea
Results The CT genotype in the TGFB1 C-509T polymorphism was associated with an increased risk of gastric cancer development (adjusted OR 1.35, $95 \%$ CI $1.07-1.71, P=0.013$ ), especially for intestinal-type cancer (adjusted OR 1.43, $95 \%$ CI 1.08-1.90, $P=0.014$ ). More frequent TGF- $\beta 1$ expression was found in the center of cancer tissue in the TGFB1-509T carrier group than in the others $(90.5 \%$ vs. $72.2 \%, P=0.010)$. T-carriers also presented higher expression level of gastric TGF- $\beta 1$ mRNA than non T-carriers (median 1.29 vs. 0.80, $P=0.004$ ) when they were infected by $H$. pylori. Cancer patients showed elevated gastric TGFBlgene expression compared to the control group (median 1.22 vs. 0.89, $P=0.009$ ).

Conclusions The carcinogenic effect of TGF- $\beta 1$ might be associated with increased gastric TGF- $\beta 1$ expression in subjects with the T allele of TGFB1-509.

Keywords TGFB1 - TGF- $\beta 1$ - Gastric cancer - Genetic polymorphism $\cdot$ H. pylori

\section{Introduction}

The age-standardized incidence of gastric cancer is decreasing, but it is still one of the most prevalent neoplasms, especially in East Asia. In Korea, although the 5-year survival rate has increased up to $67 \%$, gastric cancer still accounts for the majority of cancer-related mortality [1]. This is mainly because of limited therapeutic choices in later stages; thus, understanding of risk factors for gastric cancer is very important to prevent this disease.

Helicobacter pylori infection, environmental and genetic factors are commonly considered to be involved in the carcinogenesis of gastric cancer, but the exact 
molecular or genomic process of transformation to gastric cancer remains unclear. Among genetic alterations, single nucleotide polymorphic genes have been implicated as potential candidates for increased cancer susceptibility. In particular, transforming growth factor-beta (TGF- $\beta$ ) has garnered much attention because of its dual role as tumor suppressor and promoter. It is known that TGF- $\beta$ has antiproliferative action in normal epithelial cells in the early stages of oncogenesis but promotes tumorigenesis in the late phase of tumor development, partially through induction of epithelial-to-mesenchymal transition (EMT), which contributes to tumor progression, invasion and metastasis $[2,3]$. TGF- $\beta$ has three isoforms, TGF- $\beta 1,2$ and 3 , but most studies have examined TGF- $\beta 1$ because of its predominant and universal expression [3]. Since Grainger et al. [4] identified elevated serum levels of TGF- $\beta 1$ in healthy twins carrying TGFB1-509T homozygote, TGFB1 C-509T (rs1800469) has been investigated because of its presence in the promoter region [5]. This implies that TGF$\beta 1$ production might be under the control of the TGFB1 gene, and different predispositions of this single nucleotide polymorphism (SNP) could influence the gastric cancer risk. However, despite several previous studies on this SNP, the relationship to gastric cancer development remains controversial [6-10]. Furthermore, virtually nothing is known about the effect of this genetic polymorphism on TGF- $\beta 1$ expression in the gastric mucosa.

Therefore, we performed genotype analyses for the C-509T polymorphism in the TGFBl gene and compared its frequency between gastric cancer patients and controls in a single center in Korea. Moreover, gastric expression of TGF- $\beta 1$ was also measured and compared according to the TGFB1 C-509T genotype, cancer stage, histologic type and $H$. pylori infection.

\section{Materials and methods}

\section{Patient selection}

From February 2006 to March 2014, patients who visited our gastroenterology department at Seoul National University Bundang Hospital and underwent upper gastroduodenal endoscopy were prospectively recruited. During endoscopy, apart from cancer tissue in gastric cancer cases, two pairs of biopsies were taken from normal-appearing gastric mucosa in both the antrum and body for histological evaluation, determination of $H$. pylori infection status genotyping and measurement of TGFB1 mRNA. The participants were divided into cancer and healthy control groups according to pathologic results. Blood samples for serologic test for $H$. pylori were also obtained. Cancer tissue specimens were also obtained from patients who underwent resection either endoscopically or surgically at our hospital during this time. Patients with any other malignancy, immunosuppressive disorders, other major systemic diseases or peptic ulcer disease were excluded. Patients with gastric dysplasia were also excluded to reduce possible confounding effects from the adenomacancer sequence. Eventually, from consecutive cases who met the above-mentioned criteria, 1045 gastric cancer patients and 992 controls were enrolled. Each patient completed a questionnaire with the assistance of welltrained personnel. All subjects gave written informed consent, and the study protocol was approved by our Ethics Committee at Seoul National University Bundang Hospital.

Assessment for $H$. pylori infection

The $H$. pylori infection status was decided by modified Giemsa staining, culture and rapid urease testing (CLOtest, Delta West, Bentley, Australia). If these tests were all negative, then ${ }^{13} \mathrm{C}$-urea breath test (UBiTkit; Otsuka Pharmaceutical, Tokyo, Japan) and serum IgG specific for H. pylori were measured by an enzyme-linked immunosorbent assay (ELISA) (Genedia H. pylori ELISA; Green Cross Medical Science Corp., Eumsung, South Korea).

Transforming growth factor- $\beta 1$ genotyping

Genomic DNA was extracted from gastric antral mucosa by proteinase $\mathrm{K}$ digestion and phenol/chloroform extraction. A modified method of polymerase chain reactionrestriction fragment length polymorphism (PCR-RFLP) was performed to identify the TGFB1 C-509T genotypes. The PCR primers were $5^{\prime}$-GTA TGG GGT CGC AGG GTG TT $-3^{\prime}$ (forward) and 5'-CAG ATG CGC TGT GGC TTT GC-3' (reverse). PCR was performed at $95{ }^{\circ} \mathrm{C}$ for $5 \mathrm{~min}$ for initial denaturation followed by 40 cycles of $30 \mathrm{~s}$ at $95{ }^{\circ} \mathrm{C}, 30 \mathrm{~s}$ at $62{ }^{\circ} \mathrm{C} 30 \mathrm{~s}$, and $30 \mathrm{~s}$ at $72{ }^{\circ} \mathrm{C}$, and a final extension at $72{ }^{\circ} \mathrm{C}$ for $10 \mathrm{~min}$. The PCR products were digested overnight at $37{ }^{\circ} \mathrm{C}$ with Bsu36 I (add BSA) for TGFB1 C-509T genotypes (New England BioLabs, Beverly, MA, USA). The products were separated at $120 \mathrm{~V}$ for 45 min on a vertical $2.5 \%$ agarose gel stained with ethidium bromide. In addition, the laboratory staff was blinded to group status, and the extent of random misclassification was controlled by randomly genotyping $10 \%$ of the samples twice. We were unable to complete genotyping of 51 initially enrolled individuals, mainly because of an inadequate amount or quality of specimens; therefore, these individuals were excluded from the analysis. Finally, 958 controls and 1028 cases were successfully genotyped. 


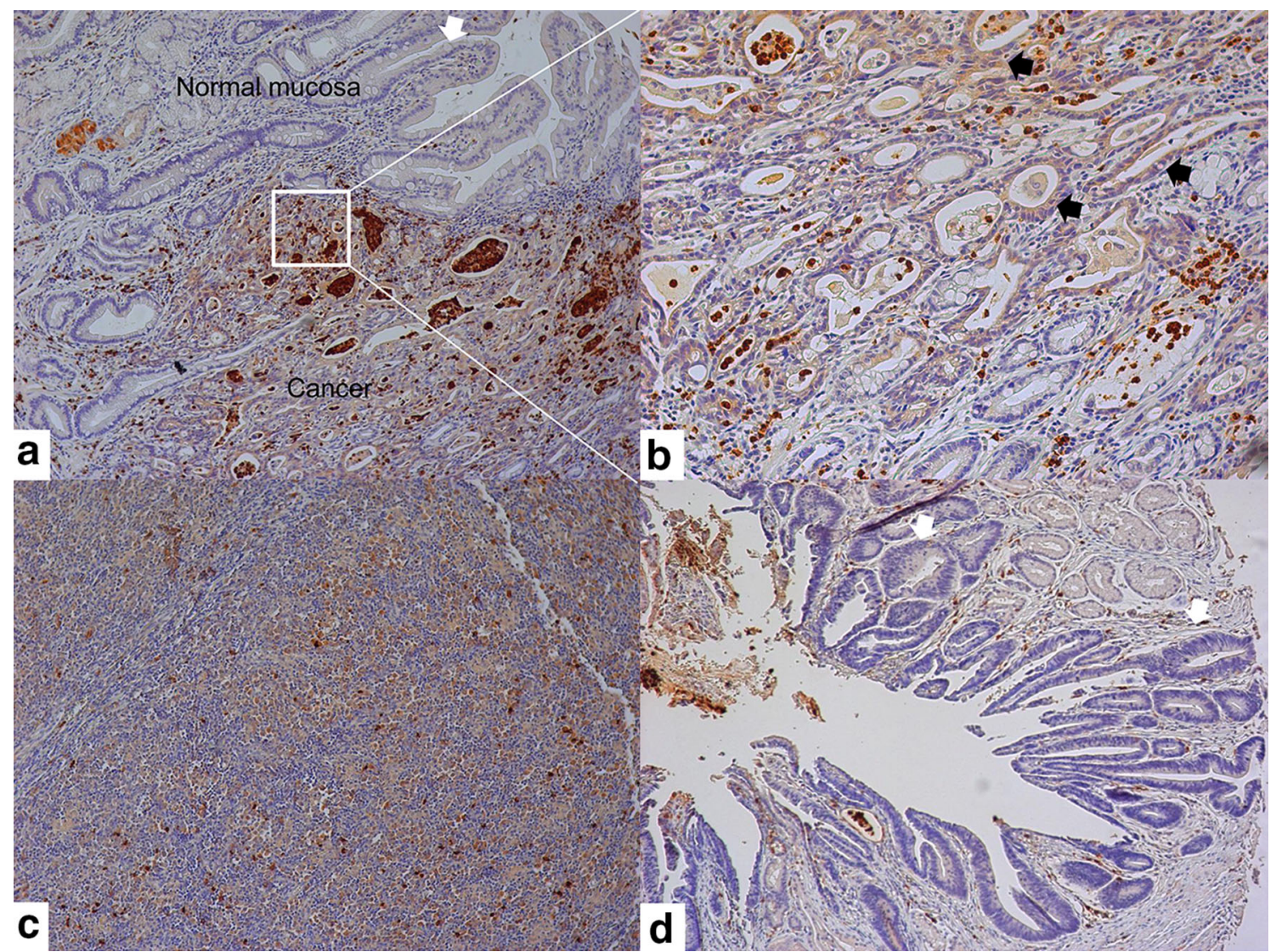

Fig. 1 Immunohistochemical findings of TGF- $\beta 1$ in gastric cancer. TGF- $\beta 1$ expression were observed in the cytoplasm of gastric cancer cells. a Peripheral part of the tumor including tumor invasive margin and normal gastric mucosa (white arrow normal gland, white box part of cancer which was magnified in b). Immunoreactivity was higher in

\section{Immunohistochemistry}

For immunohistochemical staining, 120 patients including all of $38 \mathrm{H}$. pylori-negative cases were selected among those who underwent neither neoadjuvant chemotherapy nor radiotherapy. Core tissue biopsies ( $2 \mathrm{~mm}$ in diameter) were taken from both the tumor center and peripheral part of the tumor, which included the lateral invasive margin and normal mucosa of individual paraffin-embedded gastric tumors. We defined the tumor periphery as the neoplastic lesion adjacent to this margin (Fig. 1a white box). Therefore, we measured the immunoreactivity of the cancerous lesion in the tumor center and periphery and noncancerous mucosa around the tumor's invasive margin. These cores were arranged in recipient paraffin blocks (tissue array blocks) using a trephine. The test procedure used a human control slide for immunohistochemistry (Superbiochips Laboratories). The antibody for detecting TGF- $\beta 1$ (sc-146) (Santa Cruz Biotechnology, Dallas, TX, USA) was used. Overall staining processes with sections (4 $\mathrm{lm}$ thick) from the array blocks were conducted by cancer cells compared to normal mucosa. b Positive TGF- $\beta 1$ expression in the glands (black arrows) in intestinal-type gastric cancer. c Positive TGF- $\beta 1$ expression in diffuse-type gastric cancer. d Negative TGF- $\beta 1$ expression in their glands (white arrows) of intestinal-type gastric cancer. a, c, $\mathbf{d} \times 100$, bX200

BenchMark XT Staining systems with ultraVIEW Universal DAB Detection Kit (Ventana Medical Systems, Inc., Tucson, AZ, USA).

For the immunopositivity of TGF- $\beta 1,10 \%$ of tumor cells were used as the criterion for positivity [11]. Immunostaining was further scored: 0 , no staining or in $<10 \%$ of the tumor or normal epithelial cells; $1+$, faint/barely perceptible partial staining in $>10 \% ; 2+$, weak to moderate staining in $>10 \% ; 3+$, strong staining in $>10 \%$ of the tumor or normal epithelial cells [12]. Each sample was scored in a blind manner.

\section{Measurement of TGFB1 mRNA expression}

Gastric body mucosa was stored in liquid nitrogen. From this cohort, 282 samples were selected because of the availability and quality of RNA (RNA integrity no. 1.7-1.9 measured on a NanoDrop $2000^{\circledR}$ ThermoScientific, Wilmington, DE, USA). Total RNA was purified from tissues using Trizol ${ }^{\circledR}$ reagent (Invitrogen, Carlsbad, CA, USA). Using M-MLV reverse transcriptase (Invitrogen), the total 
RNA was reverse transcribed according to the manufacturer's protocols. To quantify (TGF- $\beta 1$ ) expressions, realtime quantitative RT-PCR was performed using an ABI PRISM $^{\circledR} 7000$ Sequence Detection System (Applied Biosystems, Foster City, CA, USA). The sense primer for TGFB1 was 5'-AGG GCT ACC ATG CCA ACT TCT-3', and the antisense primer was $5^{\prime}$-CCG GGT TAT GCT GGT TGT ACA-3'. The reaction mixture was prepared according to the manufacturer's protocol using $\mathrm{SYBR}^{\circledR}$ Premix Ex Taq $^{\mathrm{TM}}$ (TaKaRa, Shiga, Japan). The thermal cycling conditions included $95{ }^{\circ} \mathrm{C}$ for $30 \mathrm{~s}$ then 40 cycles of $95{ }^{\circ} \mathrm{C}$ for $5 \mathrm{~s}, 60^{\circ} \mathrm{C}$ for $34 \mathrm{~s}$ and melting curve stage for $95^{\circ} \mathrm{C}$ for $15 \mathrm{~s}, 60^{\circ} \mathrm{C}$ for $1 \mathrm{~min}$ and $95^{\circ} \mathrm{C}$ for $15 \mathrm{~s}$. Nonspecific amplifications of mRNA were excluded by screening amplification plot analysis of ABI 7000 software v1.2.3, justifying the low false-positive rate. The expression level of the TGFBl gene was presented as relative gene expression compared with an endogenous control, $\beta$-actin, using the $2^{-\Delta \Delta C \mathrm{t}}$ method [13].

\section{Statistical Analysis}

Differences in clinicopathological variables and the trend of genotype frequency between cases and controls were evaluated using the chi-square and the Cochran-Armitage chi-square test. The associations between TGFBl polymorphisms and gastric cancer risk were estimated by computing the odds ratio (OR) and their $95 \%$ confidence intervals (CIs) from multivariate logistic regression analyses with adjustment for age (modeled as a categorical variable; $<40,40-60$, $\geq 60$ ), gender, cigarette smoking, alcohol consumption, regular spicy food ingestion, childhood residential area, $H$. pylori infection status, and family history of gastric cancer. Additionally, we analyzed the data by cancer stage and Lauren classification using polynomial logistic regression models. Hardy-Weinberg equilibrium was tested using the asymptotic Pearson's chisquare test. The frequency of positive immunohistostaining, difference in the intensity according to the location where tissue was obtained in each cancer patient and expression of $T G F B 1 \mathrm{mRNA}$ were analyzed using the chisquare test, paired $t$ test and Mann-Whitney test, respectively. $P<0.05$ was considered statistically significant. Analyses were performed using the Statistical Package for the Social Sciences (version 19.0; IBM, NY, USA).

\section{Results}

Baseline characteristics of study subjects

Among 1045 gastric cancer patients and 992 controls with DNA samples, genotyping was successful in 1028 gastric cancer patients and 958 controls, and their complete genotype information was included in the final analyses. Selected demographic variables in the gastric cancer cases and controls of this study are summarized in Table 1. As shown in Table 1, male sex, age $>60$ years, presence of first-degree relatives who were affected by gastric cancer, childhood rural residence, smoking and alcohol consumption, spicy food ingestion, and $H$. pylori infection were risk factors for gastric cancer. After multivariate analysis, old age, smoking, rural childhood residency, a spicy food diet, H. pylori infection, and family history of gastric cancer among first-degree relatives were still independent risk factors for gastric cancer.

Association between TGFB1 C-509T polymorphism and gastric cancer risk

Genotype distribution of the TGFB1 C-509T polymorphism in cases and controls is shown in Table 2. The genotype frequency of this polymorphism in controls did not deviate from the Hardy-Weinberg equilibrium. The genotype frequency of TGFB1 C-509T was $23.2 \%$ (CC), $54.1 \%$ (CT), and $22.7 \%$ (TT) in the gastric cancer patients and $26.4 \%$ (CC), $47.7 \%$ (CT), and $25.9 \%$ (TT) in control subjects. This genotype frequency was different between gastric cancer patients and controls $(P=0.018)$ because of the high proportion of cases with CT genotype compared to controls. However, there was no statistically significant difference between the increased number of $\mathrm{T}$ alleles and increased risk of gastric cancer $(P=0.984)$.

After adjusting for gender, age, cigarette smoking, rural childhood residency, spicy food ingestion, $H$. pylori infection, and first-degree family history of gastric cancer, the CT genotype of C-509T was associated with a significantly increased risk of gastric cancer (adjusted OR 1.29, $95 \%$ CI 1.08-1.54, $P=0.004$ ) compared to the $-509 \mathrm{CC}$ homozygote. When we combined CT and TT genotypes assuming a dominant allele effect, the overall risk associated with gastric cancer occurrence was higher in T-carriers than in those with the CC genotype (adjusted OR 1.26, $95 \%$ CI 1.00-1.57, $P=0.046)$.

When gastric cancer patients were stratified by the Lauren classification, the CT genotype was associated with increased risk of intestinal-type gastric cancer, but not diffuse type (adjusted OR 1.43, $95 \%$ CI 1.08-1.90, $P=0.014$ ) (Table 2).

In turn, we stratified the stomach cancer patients by cancer stage in order to examine the potentially different effect of TGFB1 polymorphisms depending on tumor stage. In stage I and II cancers, the T allele in C-509T was associated with increased gastric cancer risk (adjusted OR $1.30,95 \%$ CI $1.02-1.65, P=0.035)$. However, the same allele was not associated with an increased risk of stage 
Table 1 Characteristics of gastric cancer patients and control subjects

\begin{tabular}{|c|c|c|c|c|c|c|c|c|}
\hline \multirow[t]{2}{*}{ Variable } & \multicolumn{2}{|c|}{ Control $(N=958)$} & \multicolumn{2}{|c|}{ GC patients $(N=1028)$} & \multirow[t]{2}{*}{ OR $(95 \% \mathrm{CI})$} & \multirow[t]{2}{*}{$P$ value $^{\mathrm{a}}$} & \multirow[t]{2}{*}{ Adjusted OR (95 \% CI) } & \multirow[t]{2}{*}{$P$ value ${ }^{\mathrm{b}}$} \\
\hline & $n$ & $\%$ & $n$ & $\%$ & & & & \\
\hline Male & 514 & 53.7 & 685 & 66.6 & $1.73(1.44-2.07)$ & $<0.001$ & $1.00(0.75-1.34)$ & 0.983 \\
\hline \multicolumn{9}{|l|}{ Age (years) } \\
\hline$<39$ & 138 & 14.4 & 58 & 5.6 & & $<0.001$ & 1.00 (referent) & \\
\hline $40-60$ & 413 & 43.1 & 387 & 37.6 & $2.23(1.59-3.12)$ & & $1.86(1.30-2.68)$ & 0.001 \\
\hline$\geq 60$ & 407 & 42.5 & 583 & 56.7 & $3.41(2.45-4.75)$ & & $3.02(2.11-4.33)$ & $<0.001$ \\
\hline First-degree GC relatives & 98 & 10.2 & 206 & 20.0 & $2.20(1.70-2.85)$ & $<0.001$ & $2.15(1.62-2.86)$ & $<0.001$ \\
\hline \multicolumn{9}{|l|}{ Residency in childhood } \\
\hline Rural area & 399 & 43.1 & 590 & 60.1 & $1.99(1.66-2.39)$ & $<0.001$ & $1.76(1.45-2.14)$ & $<0.001$ \\
\hline Urban area & 526 & 56.9 & 391 & 39.9 & & & & \\
\hline \multicolumn{9}{|l|}{ Smoking status } \\
\hline Current/ex-smoker & 447 & 47.0 & 629 & 61.2 & $1.78(1.49-2.13)$ & $<0.001$ & $1.67(1.26-2.21)$ & $<0.001$ \\
\hline Nonsmoker & 504 & 53.0 & 398 & 38.8 & & & & \\
\hline \multicolumn{9}{|l|}{ Alcohol consumption } \\
\hline Drinker & 447 & 47.1 & 572 & 55.7 & $1.42(1.19-1.69)$ & $<0.001$ & $1.12(0.90-1.40)$ & 0.314 \\
\hline Non-drinker & 503 & 52.9 & 454 & 44.3 & & & & \\
\hline Spicy food ingestion & & & & & & $<0.001$ & & \\
\hline Moderate/strong & 628 & 67.9 & 765 & 78.3 & $1.71(1.39-2.10)$ & & $1.64(1.32-2.04)$ & $<0.001$ \\
\hline Low & 297 & 32.1 & 212 & 21.7 & & & & \\
\hline H. pylori $(+)$ & 719 & 75.1 & $884^{\mathrm{c}}$ & 86.0 & $2.03(1.62-2.56)$ & $<0.001$ & $2.00(1.55-2.58)$ & $<0.001$ \\
\hline \multicolumn{9}{|l|}{ Atrophy } \\
\hline Antrum & $243 / 568$ & 42.8 & $369 / 571$ & 64.6 & & & & \\
\hline Body & $117 / 628$ & 18.6 & $273 / 644$ & 42.4 & & & & \\
\hline \multicolumn{9}{|l|}{ Intestinal metaplasia } \\
\hline Antrum & $304 / 938$ & 32.4 & $677 / 1010$ & 67.0 & & & & \\
\hline Body & $161 / 940$ & 17.1 & $453 / 1012$ & 44.8 & & & & \\
\hline \multicolumn{9}{|l|}{ Tumor location } \\
\hline Non-cardia & & & 955 & 92.9 & & & & \\
\hline Cardia & & & 73 & 7.1 & & & & \\
\hline \multicolumn{9}{|l|}{ Histologic type } \\
\hline Intestinal & & & 598 & 58.2 & & & & \\
\hline Diffuse & & & 407 & 39.6 & & & & \\
\hline Others $^{c}$ & & & 23 & 2.2 & & & & \\
\hline \multicolumn{9}{|l|}{ Cancer stage $^{\mathrm{d}}$} \\
\hline Stage I, II & & & 759 & 73.8 & & & & \\
\hline Stage III, IV & & & 269 & 26.2 & & & & \\
\hline
\end{tabular}

$G C$ gastric cancer, $O R$ odds ratio, $C I$ confidential interval

${ }^{a} P$ value: by chi-square test

${ }^{\mathrm{b}} P$ value: by multiple logistic regression adjusted for sex, age, cigarette smoking, alcohol consumption, spicy food ingestion, $H$. pylori infection, and first-degree family history of gastric cancer

${ }^{c}$ Case: Twenty-three cancer patients with mixed or indeterminate type were excluded

d TNM stage was judged by the AJCC, 7th edition

III + IV gastric cancer (adjusted OR 1.15, $95 \%$ CI 0.82-1.61, $P=0.417$ ) (Table 3).

When the stomach cancer cases were stratified into noncardia and cardia cancers by location of cancer, $73(7.6 \%)$ cases were cardia cancer. The T carrier of the TGFB1-509 was associated with increased susceptibility to non-cardia gastric cancer (adjusted OR 1.26, $95 \%$ CI 1.00-1.58, $P=0.044)$, while there was no significant association between any genotypes of this SNP and cardia cancer (data not shown). 


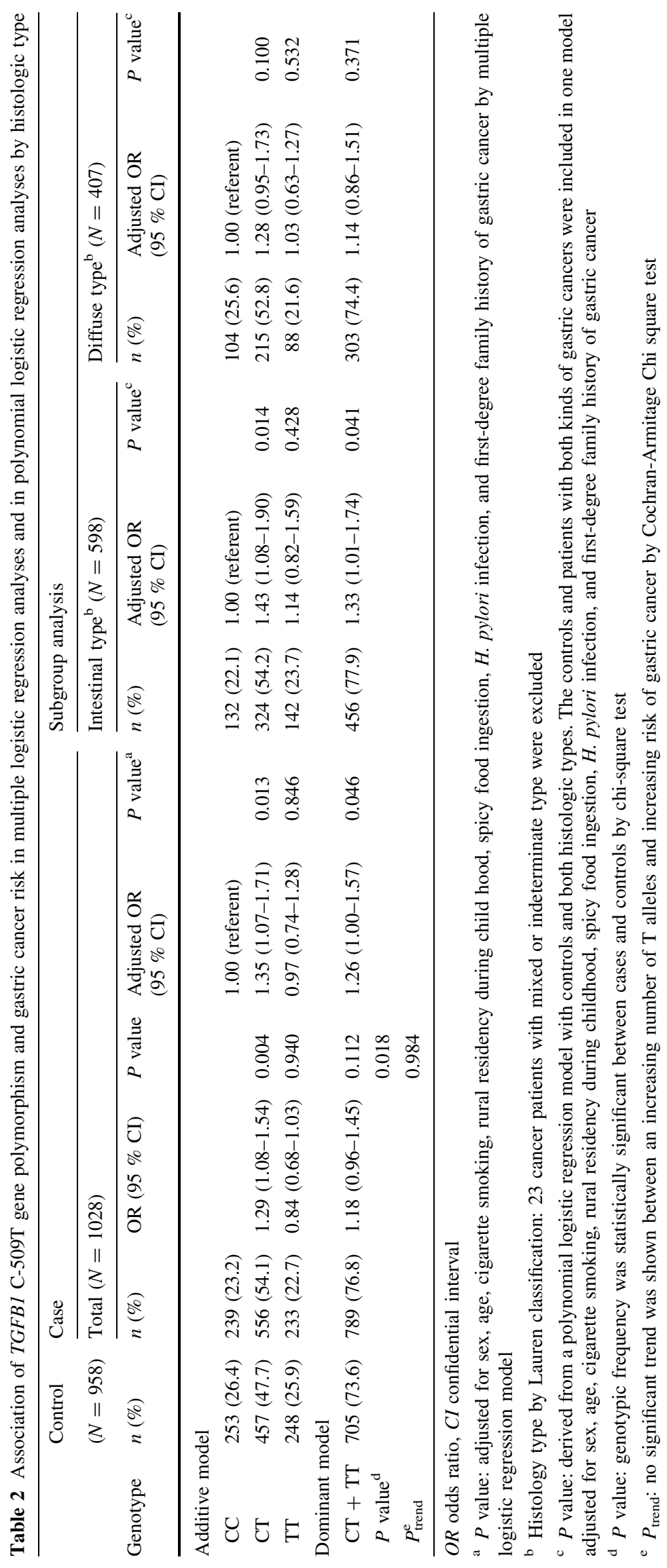


Table 3 Association of the TGFB1 C-509T gene polymorphism with gastric cancer risk depending on TNM stage in polynomial logistic regression analyses

\begin{tabular}{|c|c|c|c|c|c|c|c|}
\hline \multirow[b]{3}{*}{ Genotype } & \multirow{3}{*}{$\begin{array}{l}\text { Control } \\
(N=958) \\
n(\%)\end{array}$} & \multicolumn{6}{|l|}{ Case } \\
\hline & & \multicolumn{3}{|c|}{ TNM stage I + II $(N=759)$} & \multicolumn{3}{|c|}{ TNM stage III + IV $(N=269)$} \\
\hline & & $n(\%)$ & Adjusted OR (95\% CI) & $P$ value $^{\mathrm{a}}$ & $n(\%)$ & Adjusted OR (95 \% CI) & $P$ value $^{\mathrm{a}}$ \\
\hline \multicolumn{8}{|c|}{ Additive model } \\
\hline $\mathrm{CC}$ & $253(26.4)$ & $177(23.3)$ & 1.00 (referent) & & $62(23.0)$ & 1.00 (referent) & \\
\hline CT & $457(47.7)$ & $417(54.9)$ & $1.46(1.13-1.88)$ & 0.004 & $139(51.7)$ & $1.22(0.86-1.74)$ & 0.266 \\
\hline TT & $248(25.9)$ & $165(21.7)$ & $1.03(0.76-1.39)$ & 0.854 & $68(25.3)$ & $1.03(0.68-1.55)$ & 0.906 \\
\hline \multicolumn{8}{|c|}{ Dominant model } \\
\hline $\mathrm{CT}+\mathrm{TT}$ & $705(73.6)$ & $582(76.6)$ & $1.30(1.02-1.65)$ & 0.035 & $207(77.0)$ & $1.15(0.82-1.61)$ & 0.417 \\
\hline
\end{tabular}

TNM stage was judged by AJCC, 7th edition

$O R$ odds ratio, $C I$ confidential interval, TNM tumor-node-metastasis

${ }^{\text {a }} P$ value: derived from a polynomial logistic regression model with controls and both stages I + II and III + IV, adjusted for sex, age, cigarette smoking, rural residency during child hood, spicy food ingestion, H. pylori infection, and first-degree family history of gastric cancer

Expression of TGF- $\beta 1$ in cancerous mucosa

A total of 120 gastric cancer patients including $38 \mathrm{H}$. pylorinegative cases were analyzed (Supplementary Table 1). TGF- $\beta 1$ protein analyses exhibited predominantly cytoplasmic immunostaining (Fig. 1a, b, c). Regarding the center of gastric cancer tissue, TGF- $\beta 1$ expression was observed in tumor cells in $102(85 \%)$ out of 120 gastric cancers. When this was stratified by TGFB1-509 genotype, 57 (90.5\%) of 63 tumor centers with the CT genotype showed positive TGF- $\beta 1$ expression, while 26 (72.2\%) of 36 tumor centers with the CC genotype expressed $72.2 \%$ of immunopositivity $(P=0.018$, Table 4$)$. Nineteen $(90.5 \%)$ of 21 tumor centers with the TT genotype also displayed positive TGF$\beta 1$ immunoreactivity, but this did not reach statistical significance, probably because of the small sample size of the TT genotype. The neoplastic and non-neoplastic lesion around the lateral tumor margin in the patients with the $\mathrm{T}$ allele showed more frequent expression of TGF- $\beta 1$ compared to the non T-carriers, but did not obtain statistical significance either.

In terms of $H$. pylori infection, $H$. pylori-positive gastric cancer patients were more likely to exhibit stronger immunostaining in noncancerous tissue, but not in tumor compared to $H$. pylori-negative patients by paired $t$ test $(1.16 \pm 0.21$ vs. $0.42 \pm 0.16,1.68 \pm 0.18$ vs. $1.51 \pm 0.18$ and $1.77 \pm 0.16$ vs. $1.32 \pm 0.21, P=0.026, P=0.574$ and $P=0.124)$. However, no significant differences were found according to the histologic type, stage and location of cancer.

For the comparison of TGF- $\beta 1$ expression between the center and periphery of the tumor and between cancerous and peritumoral noncancerous mucosa, the intensity of immunostaining was scored. While noncancerous mucosal tissue showed a lower score than both central and peripheral tumor tissue $(0.76 \pm 0.09$ vs. $1.53 \pm 0.09$ and $1.52 \pm 0.10$, all $P<0.001$ ), there was no significant difference between the center and peripheral tumor tissue.

mRNA expression of TGFB1 in noncancerous gastric mucosa

TGFB1 mRNA levels in normal-appearing gastric mucosa were measured in 282 subjects (Table 5). Their clinicopathological characteristics are shown in Supplementary Table 2. Subjects carrying the CC genotype showed the lowest TGF- $\beta 1$ level in gastric mucosa compared with those who had the other two genotypes (CC vs. CT $P=0.003$, CC vs. TT $P=0.084)$. Overall, T-carriers presented higher levels of gastric TGFBl mRNA than non T-carriers (median 1.29 vs. 0.80, $P=0.004$ ). H. pyloripositive subjects expressed significantly higher levels of the gene than $H$. pylori-negative subjects (median 1.22 vs. $0.95, P=0.041)$. Cancer patients showed elevated gastric gene expression compared to the control group (median 1.22 vs. $0.89, P=0.009$ ).

When stratified by the Lauren criteria, the gene was upregulated in patients with intestinal-type cancer compared to that in controls (median 1.25 vs. $0.89, P=0.006$ ). Furthermore, the differences between the stage I + II and the control group (median 0.89 vs.1.18, $P=0.040$ ) and between the III + IV and the control group (median 0.89 vs. $1.38, P=0.010$ ) were statistically significant. However, the difference between the stage I + II (median 1.18) and stage III + IV groups (median 1.38) did not reach statistical significance, perhaps because of the small sample size of advanced stage cases. Otherwise, no statistically significant differences were found between the two groups according to histologic types or presence of family history of gastric cancer among first-degree relatives. 
Table 4 Immunoreactivity of TGF- $\beta 1$ in 120 gastric cancer specimens according to clinicopathological parameters

Bold style indicates statistical significance

${ }^{\text {a }}$ Cancerous tissue that includes the tumor invasive margin and adjacent to normal tissue

b Peritumoral noncancerous mucosa. Some of the specimens did not contain normal mucosa in their array section

${ }^{c} P$ values are described in order of center, periphery and noncancerous

d Analyzed by paired $t$ test because this pool had been intended primarily for comparison between $H$. pyloripositive and -negative subjects by age and sex matching

e Scored in the manner described in the Methods section

\begin{tabular}{lll}
\hline Variable & Cancer & $\begin{array}{l}\text { Noncancerous }^{\mathrm{b}} \quad P \text { value }^{\mathrm{c}} \\
\end{array}$ \\
Center $(+)$ & $\begin{array}{l}\text { Periphery }^{\mathrm{a}} \\
(+)\end{array}$ & $(+)$
\end{tabular}

\begin{tabular}{|c|c|c|c|c|}
\hline \multicolumn{5}{|l|}{ TGFB1-509 CT genotype } \\
\hline $\mathrm{CC}(n=36)(\%)$ & $26 / 36(72.2)$ & $24 / 32(75.0)$ & $11 / 23(47.8)$ & $\begin{array}{l}\text { CC vs. CT } \mathbf{0 . 0 1 8}, 0.624, \\
0.748\end{array}$ \\
\hline $\mathrm{CT}(n=63)(\%)$ & $57 / 63(90.5)$ & $46 / 59(78.0)$ & $27 / 50(51.9)$ & $\begin{array}{l}\text { CC vs. TT } 0.177,0.494, \\
0.142\end{array}$ \\
\hline $\mathrm{TT}(n=21)(\%)$ & $19 / 21(90.5)$ & $18 / 21(85.7)$ & $14 / 20(70.0)$ & $\begin{array}{l}\text { CT vs. TT } 0.990,0.446, \\
0.220\end{array}$ \\
\hline $\begin{array}{l}\text { Non T-carrier }(n=36) \\
(\%)\end{array}$ & $26 / 36(72.2)$ & $24 / 32(75.0)$ & $11 / 23(47.8)$ & $\mathbf{0 . 0 1 0}, 0.560,0.368$ \\
\hline T carrier $(n=84)(\%)$ & $76 / 84(90.5)$ & $64 / 80(80.0)$ & $41 / 70(58.6)$ & \\
\hline \multicolumn{5}{|l|}{ H. pylori infection } \\
\hline $\begin{array}{l}\text { Positive }(n=82) \\
\quad(\text { mean } \pm \mathrm{SE})^{\mathrm{d}}\end{array}$ & $1.68 \pm 0.18$ & $1.77 \pm 0.16$ & $1.16 \pm 0.21$ & $0.574,0.124, \mathbf{0 . 0 2 6}$ \\
\hline $\begin{array}{l}\text { Negative }(n=38) \\
\quad(\text { mean } \pm \text { SE })^{\mathrm{d}}\end{array}$ & $1.51 \pm 0.18$ & $1.32 \pm 0.21$ & $0.42 \pm 0.16$ & \\
\hline \multicolumn{5}{|l|}{ Histology $\mathrm{y}^{\mathrm{a}}$} \\
\hline $\begin{array}{l}\text { Intestinal type }(n=67) \\
\quad(\%)\end{array}$ & $59 / 67(88.1)$ & $52 / 64(84.4)$ & $34 / 53(64.2)$ & $0.291,0.084,0.066$ \\
\hline Diffuse type $(n=53)(\%)$ & $43 / 53(81.1)$ & $34 / 48(70.8)$ & $18 / 40(45.0)$ & \\
\hline \multicolumn{5}{|l|}{ Cancer stage ${ }^{\mathrm{b}}$} \\
\hline Stage I + II $(n=99)(\%)$ & $87 / 99(87.9)$ & 70/91 (76.9) & $46 / 78(59.0)$ & $0.055,0.376,0.175$ \\
\hline $\begin{array}{l}\text { Stage III + IV }(n=21) \\
\quad(\%)\end{array}$ & $15 / 21(71.4)$ & $18 / 21(85.7)$ & $6 / 15(40.0)$ & \\
\hline \multicolumn{5}{|l|}{ Location } \\
\hline Non-cardia $(n=111)(\%)$ & $\begin{array}{r}93 / 111 \\
(83.8)\end{array}$ & $\begin{array}{r}80 / 103 \\
(77.7)\end{array}$ & $47 / 87(54.0)$ & $0.190,0.432,0.162$ \\
\hline Cardia $(n=9)(\%)$ & 9/9 (100) & $8 / 9(88.9)$ & $5 / 6(83.3)$ & \\
\hline Immunoreactive score & $1.53 \pm 0.09$ & $1.52 \pm 0.10$ & $0.76 \pm 0.09$ & Center vs. periphery 0.922 \\
\hline \multirow[t]{2}{*}{$(\text { Mean } \pm \mathrm{SE})^{\mathrm{e}}$} & & 0.922 & $<0.001$ & $\begin{array}{l}\text { Center vs. noncancerous } \\
<\mathbf{0 . 0 0 1}\end{array}$ \\
\hline & & & & $\begin{array}{l}\text { Periphery vs. noncancerous } \\
\quad<\mathbf{0 . 0 0 1}\end{array}$ \\
\hline
\end{tabular}

When the analyses were stratified by the presence of a $\mathrm{T}$ allele and the stage, T-carriers in stage I + II showed significantly higher expression of gastric TGF- $\beta 1$ than non T-carriers (median 1.28 vs. $0.80, P=0.044$ ) (Fig. $2 \mathrm{a}$ ). Next, the analyses were stratified by the presence of the T allele and $H$. pylori infection status. In the $H$. pyloripositive subjects, $\mathrm{T}$ carriers showed significantly higher gene expression compared to $\mathrm{CC}$ homozygotes (median 0.83 vs. $1.90, P<0.001$ ), while no significant genotypic difference was detected in the $H$. pylori-negative subjects (median: 0.80 vs. $0.98, P=0.734$ ) (Fig .2b). When the analyses were restricted to each control subject and cancer patient, the result was similar (cancer patients; $H$. pylori positive 1.05 vs. $2.13, P=0.014$ and $H$. pylori negative 1.05 vs. $1.13, P=0.567$ ) (control subjects; $H$. pylori positive: 0.45 vs. $1.70, P=0.041$ and $H$. pylori negative 0.59 vs. $0.89, P=0.463)$.
When multiple linear regression analysis by log transformation was conducted with cancer stage (I + II, III + IV), carrying of the T allele and $H$. pylori infection, which showed a statistically significant difference in univariate analyses, gastric expression of TGF- $\beta 1$ in noncancerous mucosa was greater in the cases of stage III + IV cancer or those who harbored $\mathrm{T}$ allele in TGFB1 C-509T ( $\beta=1.151$ and $1.179, P=0.025$ and 0.006 , respectively).

\section{Discussion}

We set out to determine the association between the TGFB1 C-509T polymorphism and the risk for gastric cancer in this case-control study. There was a significant association between the $-509 \mathrm{CT}$ genotype and increased 
Table 5 Gastric expression of TGFB1 mRNA levels by qRTPCR according to clinicopathological parameters

FHx family history of gastric cancer among first-degree relatives

a Histology: divided by the Lauren classification

b Stage: TNM stage was judged by AJCC, 7th edition

${ }^{c} P$ value: calculated by MannWhitney test

\begin{tabular}{|c|c|c|}
\hline Variable & $\begin{array}{l}\text { Relative expression of } T G F B 1 \\
\text { mRNA (median, range) }\end{array}$ & $P$ value $^{\mathrm{c}}$ \\
\hline \multicolumn{3}{|l|}{ TGFB1-509 genotype } \\
\hline $\mathrm{CC}(n=101)$ & $0.80(0.01-12.91)$ & CC vs. CT 0.003 \\
\hline $\mathrm{CT}(n=113)$ & $1.31(0.02-30.27)$ & CT vs. TT 0.282 \\
\hline $\mathrm{TT}(n=68)$ & $1.21(0.01-11.80)$ & CC vs. TT 0.084 \\
\hline $\mathrm{T}$ carrier $(n=181)$ & $1.29(0.01-30.27)$ & 0.004 \\
\hline Non T-carrier $(n=101)$ & $0.80(0.01-12.91)$ & \\
\hline \multicolumn{3}{|l|}{ H. pylori infection } \\
\hline Positive $(n=159)$ & $1.22(0.01-30.27)$ & 0.041 \\
\hline Negative $(n=123)$ & $0.95(0.02-12.91)$ & \\
\hline \multicolumn{3}{|l|}{ Histology $^{\mathrm{a}}$} \\
\hline Control $(n=125)$ & $0.89(0.03-15.40)$ & Control vs. intestinal type 0.006 \\
\hline Intestinal type $(n=110)$ & $1.25(0.01-30.27)$ & Control vs. diffuse type 0.455 \\
\hline Diffuse type $(n=47)$ & $0.94(0.01-28.07)$ & Intestinal vs. diffuse 0.219 \\
\hline \multicolumn{3}{|l|}{ Cancer stage } \\
\hline Control $(n=125)$ & $0.89(0.03-15.40)$ & Control vs. cancer 0.009 \\
\hline Cancer $(n=157)$ & $1.22(0.01-30.27)$ & Control vs. stage I + II cancer 0.040 \\
\hline Stage $^{\mathrm{b}} \mathrm{I}+\mathrm{II}(n=122)$ & $1.18(0.01-30.27)$ & Control vs. stage III + IV cancer 0.010 \\
\hline Stage $^{\mathrm{b}}$ III + IV $(n=35)$ & $1.38(0.02-23.34)$ & Stage I + II vs. stage III + IV cancer 0.258 \\
\hline \multicolumn{3}{|l|}{ FHx } \\
\hline FHx $(-)$ control $(n=32)$ & $0.72(0.10-9.99)$ & 0.743 \\
\hline FHx $(+)$ control $(n=93)$ & $0.95(0.03-15.40)$ & \\
\hline FHx $(-)$ cancer $(n=76)$ & $1.31(0.01-28.07)$ & 0.179 \\
\hline FHx $(+)$ cancer $(n=81)$ & $1.17(0.01-30.27)$ & \\
\hline
\end{tabular}

risk of developing gastric cancer, especially in intestinal type.

In the present study, TGFB1 mRNA expression in normal gastric mucosa and TGF- $\beta 1$ expression in cancerous mucosa were also more abundant in those with the $-509 \mathrm{~T}$ allele than in the others. Our functional analysis suggests that SNP rs1800469 in the TGFB1 promoter could modulate mRNA and protein levels and therefore might be related to cancer development.

Similarly, there have been previous studies suggesting that the $-509 \mathrm{~T}$ allele is associated with the development of neoplasms, such as colorectal adenoma [14] and melanoma [15]. As for gastric cancer, two Chinese studies reported that the CT and TT genotypes were significantly related to cancer risk compared with the CC genotype $[6,16]$. A recent meta-analysis with 2130 cases and 2374 controls from 7 published case-control studies concluded that the TGFB1-509T allele is a susceptibility factor for gastric cancer [17]. However, contradictory data have also been reported. Other Chinese studies proposed that $-509 \mathrm{~T}$ allele carriers were at lower risk for developing gastric cancer than their counterparts with the $\mathrm{C}$ allele $[9,10]$. The inconsistency among these studies may be explained by ethnic differences in allelic frequency. The frequency of the -509 TT genotype in controls of one study from south
India was only $6 \%$ [7], far less than ours. Furthermore, the allelic frequency of TGFB1-509T varies, ranging from 32.8 to $49.2 \%$ even in the Chinese population [6-10, 16, 18].

In the present study, we compared the gastric gene and protein expression according to different genotypes, whereas other associated factor studies only conducted analyses for genotype frequency and gastric cancer. Higher levels of gastric TGF- $\beta 1$ expression in cancer tissue of $-509 \mathrm{~T}$ carriers were shown compared to those with $\mathrm{CC}$ genotype. Unfortunately, a significant difference was not found in either gene or protein expression between the TT and CT genotypes, probably because of the small number of $\mathrm{T}$ homozygotes whose TGF- $\beta 1$ expression was evaluated.

On the other hand, the influence of TGF- $\beta 1$ upregulation in the gastric mucosa on tumorigenesis could be inversely interpreted because of its dual effects, but several studies suggest the experimental relevance between increased TGF- $\beta 1$ expression and tumor formation. Enhanced metabolic rate, adhesiveness, and survival were observed in the TGF- $\beta 1$-overexpressing cells. When introduced into nude mice, these engineered tumor cells showed an increment in tumorigenicity [19].

Of particular note is that, in our study, normal-appearing peritumoral tissue itself showed elevated gene expression in the $\mathrm{T}$ carriers compared to non T-carriers and in cancer 


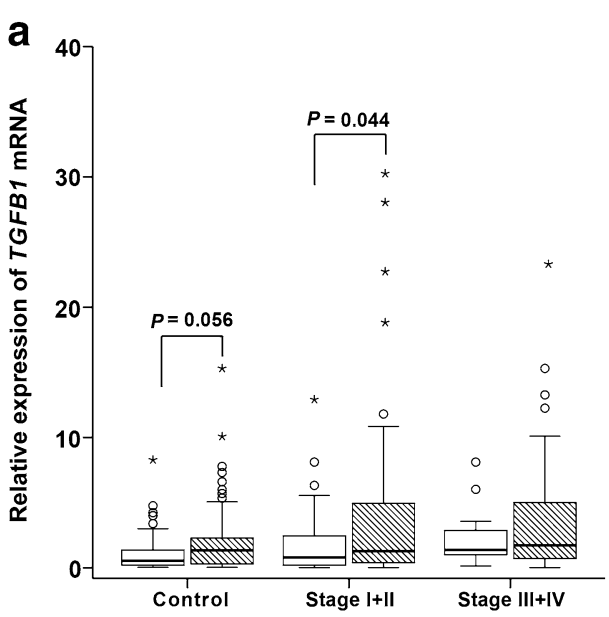

Fig. 2 TGFB1 mRNA expression in gastric mucosa as measured by quantitative RT-PCR. Expression was quantified in relation to the expression of beta-actin as a reference gene. a Gastric TGFB1 mRNA expression by different TGFB1 C-509T genotype and TNM stages. Generally, T-carriers tended to have upregulation of gastric TGFB1 mRNA expression compared to non-T-carriers, but a statistically significant difference was shown only in stage I + II cases by the Mann-Whitney test $(P=0.044)$. b Gastric TGFB1 mRNA expression by different TGFB1 C-509T genotype and $H$. pylori infection statuses.

patients compared to controls. Although the immunohistochemistry findings did not reach statistical significance, $\mathrm{T}$ homozygotes expressed the positive staining more frequently than $\mathrm{C}$ homozygotes in non-neoplastic peritumoral mucosa (70.0 vs. $47.8 \%$ ). This might be derived from the difficulty in discerning differences in very faint immunoreactivity of peritumoral noncancerous mucosa.

According to the general consensus that TGF- $\beta$ has an antiproliferative action in normal epithelial cells at early stages but a cancer-promoting effect in the late phase of tumor development, this seems to be an unexpected result. However, a previous study reported positive staining of TGF- $\beta 1$ not only in tumor cells but also peritumoral tissue, including stromal cells [20]. Concerning the mechanism of how the tissue becomes malignant, overexpression of TGF$\beta 1$ even in noncancerous tissue in cancer patients may provide a clue about the initial carcinogenetic process, which alters the tumor environment first. It has been also reported that TGF- $\beta$ has an immunosuppressive effect [21] and enables tumor cells to escape from immune surveillance [22]. Comerci et al. [23] indicated that TGF- $\beta 1$ secreted into, or produced by, supporting stromal cells may indirectly promote tumor formation or progression.

Interestingly, the effect of the TGFBI C-509T polymorphism may be different depending on different conditions. This might be partially responsible for the inconclusive result of associational studies on this genetic polymorphism as well as ethnic heterogeneity. In the present study, the $-509 \mathrm{~T}$ allele was associated only with

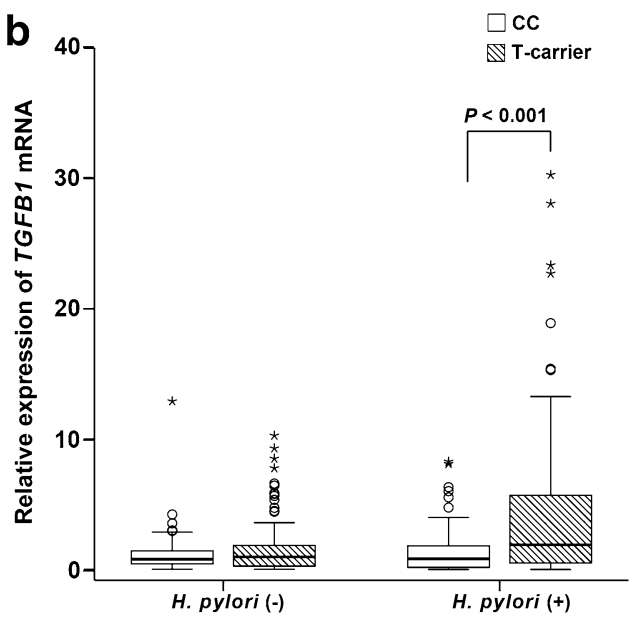

In $H$. pylori-positive subjects, T-carriers showed significantly elevated TGFB1 mRNA expression compared to those with CC $(P<0.001)$, while no difference was found in $H$. pylori-negative subjects. The whiskers in the box and whiskers plot represent the 10th and 90th percentiles. Outliers less than three interquartile ranges above the upper quartile were marked with points. Outliers more than three interquartile ranges above the upper quartile were marked with asterisks. Diagonal line patterned-bars represent T-carriers, whereas solid white bars show those with the CC genotype

intestinal-type cancer and not with diffuse-type cancer. Likewise, TGFB1 gene expression was significantly different between controls and patients with intestinal-type cancer, but not between healthy controls and those with diffuse-type cancer, in accordance with a previous report [24]. Considering that most cases of gastric cancer develop against a background of chronic atrophic gastritis or intestinal metaplasia, we inferred that TGF- $\beta 1$ may be more involved in the carcinogenesis of intestinal-type cancer related to $H$. pylori infection.

In terms of the relationship between TGF- $\beta 1$ and $H$. pylori infection, several studies have showed that $H$. pylori infection stimulates TGF- $\beta 1$ expression in tissue $[25,26]$. In line with this, higher TGF- $\beta 1$ expression in $H$. pyloripositive noncancerous tissue, not in cancerous tissue, was detected in the present study. Furthermore, subjects with the TGFB1-509T allele expressed the TGFB 1 gene more in their noncancerous mucosa when infected by $H$. pylori compared to non-T-carriers, which may predispose subjects to the development of intestinal-type GC. This difference was more evident in the noncancerous mucosa of cancer patients than that of healthy control subjects. The TGFB1 C-509T SNP could be a possible link between $H$. pylori infection and gastric cancer. Once a tumor has developed, the transcription of TGFB1 would be amplified by cancer cells themselves [27], and this might blunt the effect of $H$. pylori on cancer tissue.

However, whether this non-neoplastic mucosa produces the TGFBl gene before cancer formation or there is a role 
of elevated $T G F B 1$ gene expression in control patients with T-carriers including interaction with $H$. pylori should be further explored.

As for the effect of the TGFB1 C-509T polymorphism according to different tumor stages, a previous Chinese study indicated that $-509 \mathrm{~T}$ and $869 \mathrm{C}$ allele carriers had a decreased risk of TNM stage I + II gastric cancer [9]. Although the polymorphisms did not show any association with stage III and IV gastric cancer in the present study, the statistical power for these associations was limited by the numbers of cases in stage III and IV. For example, the minimal ORs of the statistically significant relation for a given sample size were 1.75 for TT in the additive model and 1.38 in the dominant model. Moreover, since all of the advanced cancers develop from stage I/II, different associational effects on developing cancer according to stages do not seem logical. More distribution of diffuse type cancer in stages III or IV compared to stage I and II might be responsible for lessening the potential significance (diffuse type, stage I/II vs. III/IV, $31.9 \%$ vs. $61.3 \%$, $P<0.001)$.

We also hypothesized that the tumor periphery might show more expression of TGF- $\beta 1$ than the center of cancer since EMT is known to be related with invasion of tumor cells and TGF- $\beta 1$ is a potent inducer of EMT. However, there was no significant difference in TGF- $\beta 1$ expression between the middle and peripheral part of the cancer.

Taking all things together, the TGFB1-509T allele would contribute to TGF- $\beta 1$ overexpression, and its upregulation in noncancerous tissue might have a tumorpromoting effect related to $H$. pylori infection, causing the development of intestinal-type gastric cancer.

One of the limitations of our study is the difficulty to clearly explain why the $-509 \mathrm{~T}$ heterozygote, but not homozygotes showed a significant association with an increased risk of gastric cancer. This has often been observed in other associational studies [9, 28]. Very little difference might exist between the effects of the variant homozygote and heterozygote or unexpected selection might have occurred. This might also originate from the complex role of TGF- $\beta 1$ itself, and the evaluation of only one locus in the TGFB1 gene may not explain this association sufficiently. Another limitation is that analysis of protein and gene expression was conducted in a very limited population, probably causing the failure to show a dose-dependent increase of TGF- $\beta 1$ expression. Furthermore, we analyzed the gene expression in normal mucosa without consideration of the different proximities of cancer. However, we made an effort to compensate for this by comparing immunohistostaining in normal mucosa that was adjacent to the cancer.

Nonetheless, this is the largest case-control study conducted at a single center in Korea, where relatively minimal confounding from ethnic diversity exists. By evaluating TGF- $\beta 1$ expression in relation to TGFB1 C-509T SNP not only in cancerous tissue but also in noncancerous tissue, we attempted to confirm the functional SNP and find a clue concerning whether the elevation of TGF- $\beta 1$ expression in normal tissue might be predisposed to gastric cancer.

In conclusion, we demonstrated a significantly elevated gastric TGF- $\beta 1$ expression in TGFB1 509T-carriers compared to non-T-carriers in neoplastic mucosa. Increased TGFBl gene expression in cancer patients might be related to its tumor-promoting effect and could contribute to the pathogenesis of intestinal-type gastric cancer in TGFB1-509T carriers. However, since the effect of this SNP seems modest, in order to accurately assess its clinical significance, more research is needed to clarify the exact role of $T G F B 1-509 \mathrm{~T}$ and at what point(s) in the carcinogenetic process it is involved.

Acknowledgments This work was supported by a National Research Foundation (NRF) of Korea grant for the Global Core Research Center (GCRC) funded by the Korean government (MSIP) (no. 2011-0030001). The authors are indebted to J. Patrick Barron, Professor Emeritus, Tokyo Medical University and Adjunct Professor, Seoul National University Bundang Hospital, for his pro bono editing of this manuscript. The authors thank the Division of Statistics of the Medical Research Collaborating Center at Seoul National University Bundang Hospital for statistical analyses. This work was supported by a National Research Foundation (NRF) of Korea grant for the Global Core Research Center (GCRC) funded by the Korean government (MSIP) (no. 2011-0030001).

Conflict of Interest None of the authors have conflicts of interest that could potentially influence the described research.

\section{References}

1. Jung KW, Won YJ, Kong HJ, Oh CM, Seo HG, Lee JS. Cancer statistics in Korea: incidence, mortality, survival and prevalence in 2010. Cancer Res Treat. 2013;45:1-14.

2. Larue L, Bellacosa A. Epithelial-mesenchymal transition in development and cancer: role of phosphatidylinositol $3^{\prime}$ kinase/ AKT pathways. Oncogene. 2005;24:7443-54.

3. Elliott RL, Blobe GC. Role of transforming growth factor Beta in human cancer. J Clin Oncol. 2005;23:2078-93.

4. Grainger DJ, Heathcote K, Chiano M, Snieder H, Kemp PR, Metcalfe JC, et al. Genetic control of the circulating concentration of transforming growth factor type $\beta 1$. Hum Mol Genet. 1999;8:93-7.

5. Kim SJ, Glick A, Sporn M, Roberts A. Characterization of the promoter region of the human transforming growth factor-beta 1 gene. J Biol Chem. 1989;264:402-8.

6. Guo W, Dong Z, Guo Y, Chen Z, Yang Z, Kuang G, et al. Polymorphisms of transforming growth factor- $\beta 1$ associated with increased risk of gastric cardia adenocarcinoma in north China. Int J Immunogenet. 2011;38:215-24.

7. Bhayal AC, Prabhakar B, Rao KPR, Penchikala A, Ayesha Q, Jyothy A, et al. Role of transforming growth factor- $\beta 1-509$ 
$\mathrm{C} / \mathrm{T}$ promoter polymorphism in gastric cancer in south Indian population. Tumor Biol. 2011;32:1049-53.

8. Lin X, Li C, Shi Y, Chen Y, Zhang L, Zheng X. Correlation of polymorphism of Nme1-1465 $\mathrm{T}>\mathrm{C}$ and TGF $\beta 1-509 \mathrm{~T}>\mathrm{C}$ with genetic susceptibility of gastric carcinoma. Zhonghua Bing Li Xue Za Zhi. 2010;39:681-5.

9. Zhang P, Di JZ, Zhu ZZ, Wu HM, Wang Y, Zhu G, et al. Association of transforming growth factor-beta 1 polymorphisms with genetic susceptibility to TNM stage I or II gastric cancer. Jpn J Clinl Oncol. 2008;38:861-6.

10. Jin G, Wang L, Chen W, Hu Z, Zhou Y, Tan Y, et al. Variant alleles of TGFB1 and TGFBR2 are associated with a decreased risk of gastric cancer in a Chinese population. Int $\mathrm{J}$ Cancer. 2007;120:1330-5.

11. Lee HS, Cho SB, Lee HE, Kim MA, Kim JH, Park DJ, et al. Protein expression profiling and molecular classification of gastric cancer by the tissue array method. Clin Cancer Res. 2007; 13:4154-63.

12. Ananiev J, Gulubova M, Tchernev G, Penkova M, Miteva R, Julianov A, et al. Relation between transforming growth factor$\beta 1$ expression, its receptor and clinicopathological factors and survival in HER2-negative gastric cancers. Wien Klin Wochenschr. 2011;123:668-73.

13. Schmittgen TD, Livak KJ. Analyzing real-time PCR data by the comparative CT method. Nat Protoco. 2008;3:1101-8.

14. Berndt SI, Huang WY, Chatterjee N, Yeager M, Welch R, Chanock SJ, et al. Transforming growth factor beta 1 (TGFB1) gene polymorphisms and risk of advanced colorectal adenoma. Carcinogenesis. 2007;28:1965-70.

15. Nikolova PN, Pawelec GP, Mihailova SM, Ivanova MI, Myhailova AP, Baltadjieva DN, et al. Association of cytokine gene polymorphisms with malignant melanoma in Caucasian population. Cancer Immunol Immunother. 2007;56:371-9.

16. Li T, Cao BW, Dai Y, Cui H, Yang HL, Xu CQ. Correlation of transforming growth factor beta-1 gene polymorphisms C-509T and $\mathrm{T} 869 \mathrm{C}$ and the risk of gastric cancer in China. J Gastroenterol Hepatol. 2008;23:638-42.

17. Li K, Xia F, Zhang K, Mo A, Liu L. Association of a tgf-B1509C/T polymorphism with gastric cancer risk: a meta-analysis. Ann Hum Genet. 2013;77:1-8.
18. Yu YH, Chen CX, Huang QM, Zhang J. Association of transforming growth factor beta 1 gene polymorphism and gastroauodenal diseases with Helicobaeter pyiori infection. Chin J Clin Gastroenterol. 2010;22:273-6.

19. Arrick BA, Lopez AR, Elfman F, Ebner R, Damsky CH, Derynck R. Altered metabolic and adhesive properties and increased tumorigenesis associated with increased expression of transforming growth factor beta 1. J Cell Biol. 1992;118:715-26.

20. Ma GF, Miao Q, Zeng XQ, Luo TC, Ma LL, Liu YM, et al. Transforming growth factor-beta1 and -beta2 in gastric precancer and cancer and roles in tumor-cell interactions with peripheral blood mononuclear cells in vitro. PLoS ONE. 2013;8:e54249.

21. Wakefield LM, Yang YA, Dukhanina O. Transforming growth factor-beta and breast cancer: lessons learned from genetically altered mouse models. Breast Cancer Res. 2000;2:100-6.

22. Derynck R, Akhurst RJ, Balmain A. TGF- $\beta$ signaling in tumor suppression and cancer progression. Nat Genet. 2001;29:117-29.

23. Comerci JT Jr, Runowicz CD, Flanders KC, De Victoria C, Fields AL, Kadish AS, et al. Altered expression of transforming growth factor-beta 1 in cervical neoplasia as an early biomarker in carcinogenesis of the uterine cervix. Cancer. 1996;77:1107-14.

24. Ebert M, Yu J, Miehlke S, Fei G, Lendeckel U, Ridwelski K, et al. Expression of transforming growth factor beta-1 in gastric cancer and in the gastric mucosa of first-degree relatives of patients with gastric cancer. Br J Cancer. 2000;82:1795-800.

25. Beswick EJ, Pinchuk IV, Earley RB, Schmitt DA, Reyes VE. Role of gastric epithelial cell-derived transforming growth factor $\beta$ in reduced $\mathrm{CD} 4+\mathrm{T}$ cell proliferation and development of regulatory $\mathrm{T}$ cells during Helicobacter pylori infection. Infect Immun. 2011;79:2737-45.

26. Li Z, Li J. Local expressions of TGF-beta1, TGF-beta1RI, CTGF, and Smad-7 in Helicobacter pylori-associated gastritis. Scand J Gastroenterol. 2006;41:1007-12.

27. Epstein FH, Blobe GC, Schiemann WP, Lodish HF. Role of transforming growth factor $\beta$ in human disease. $\mathrm{N}$ Engl $\mathrm{J}$ Med. 2000;342:1350-8.

28. Lee KM, Park SK, Hamajima N, Tajima K, Yoo KY, Shin A, et al. Genetic polymorphisms of TGF- $\beta 1 \&$ TNF- $\beta$ and breast cancer risk. Breast Cancer Res Treat. 2005;90:149-55. 